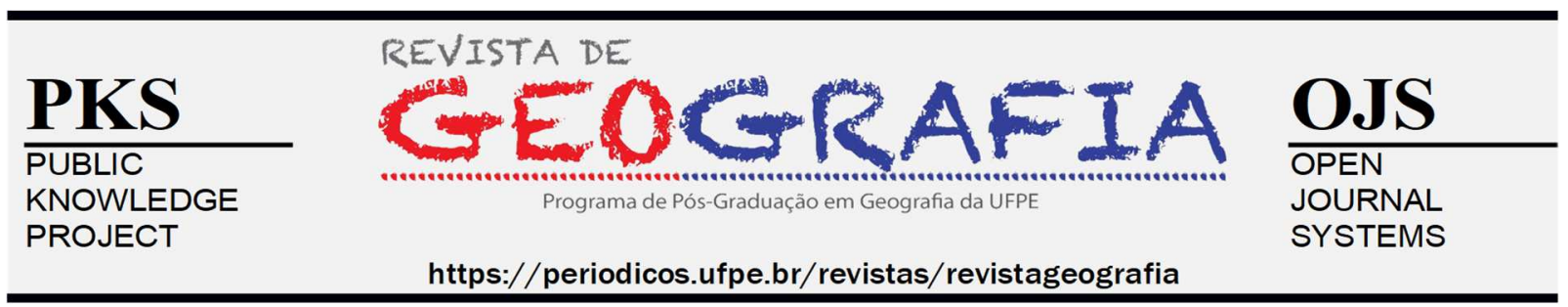

\title{
ESTUDO DA PAISAGEM LITERÁRIA DA JUIZ DE FORA (MG) DO INÍCIO DO SÉCULO XX: A IDADE DO SERROTE, DE MURILO MENDES
}

\author{
Guilherme Augusto Pereira Malta ${ }^{1}$, Humberto Fois Braga ${ }^{2}$
}

\begin{abstract}
${ }^{1}$ Doutor em Geografia na Universidade Federal de Minas Gerais, Belo Horizonte/MG. Professor vinculado ao Departamento de Turismo e ao Programa de Pós-Graduação em Geografia, da Universidade Federal de Juiz de Fora (MG). Email:guilherme.malta@gmail.com; https://orcid.org/0000-0001-8778-7763

${ }^{2}$ Doutor em Letras: Estudos Literários na Universidade Federal de Juiz de Fora, Juiz de Fora/MG. Professor vinculado ao Departamento de Turismo e ao Programa de Pós-Graduação em Letras: Estudos Literários, da Universidade Federal de Juiz de Fora (MG). Email:humfois@gmail.com; https://orcid.org/0000-0002-4179-2564
\end{abstract}

Artigo recebido em 08/10/2020 e aceito em 17/05/2021

\begin{abstract}
RESUMO
$\mathrm{O}$ artigo analisa os principais elementos formadores da paisagem literária de Juiz Fora, respaldando-se na obra memorialística A Idade do Serrote, de Murilo Mendes (1968). A partir da leitura sistemática da obra, foram selecionadas as passagens que remetem aos lugares e paisagens recorrentes, a saber: Rio Paraibuna, Avenida Barão do Rio Branco e Rua Halfeld. Ao final, percebe-se como o poeta mescla diversos tempo-espaços do imaginário ocidental na mineiridade juiz-forana: a avenida traz o aprendizado dialógico peripatético greco-antigo, já as ruas convidam a uma flânerie e ao footing da modernidade europeia, enquanto o rio transborda uma sexualidade escravocrata e colonial brasileira.
\end{abstract}

Palavras-chave: paisagem literária; $A$ idade do serrote. Juiz de Fora (MG).

\section{A STUDY OF THE LITERARY LANDSCAPE OF JUIZ DE FORA (MI- NAS GERAIS) FROM THE BEGINNING OF THE 20TH CENTURY: A IDADE DO SERROTE, BY MURILO MENDES}

\begin{abstract}
This article analyzes the main elements that compose the literary landscape of Juiz de Fora, through the memoir A Idade do Serrote, written by Murilo Mendes (1968). From a systematic reading of the book, passages related to places and recurring landscapes were selected. The ones chosen were: Paraibuna River, Barão do Rio Branco Avenue and Halfeld street. By the end of this study, it can be seen that the poet mixes several different space-times from Western imagery in the mineiridade (the feeling of belonging to the state of Minas Gerais) from Juiz de Fora. The avenue chosen brings the ancient Greek
\end{abstract}


dialogical paripatetic learning, while the streets invite to a flanerie and the modern European footing. The river overflows with a sexuality that is in tune with the slavery-based and colonial society of Brazil.

Keywords: literary landscape. A Idade do Serrote. Juiz de Fora (MG).

\title{
UNE ETUDE DU PAYSAGE LITTERAIRE DE JUIZ DE FORA (MG) DU DEBUT DU XX ${ }^{E}$ SIECLE : L'GUVRE A IDADE DO SERROTE, ECRITE PAR MURILO MENDES
}

\begin{abstract}
RESUME
L'article réfléchit sur les principaux éléments constitutifs du paysage littéraire de Juiz de Fora à partir de l'œuvre mémorialiste A Idade do Serrote (L'âge de la scie), écrite par Murilo Mendes (1968). D'après la lecture systématique de cette œuvre-là, des extraits du texte qui font des rapports aux lieux et aux paysages ont été sélectionnés, à savoir : la rivière Paraibuna, l'avenue Barão do Rio Branco et la rue Halfeld. A la fin, on se rend compte que le poète effectue un bric-à-brac de divers temps et espaces spécifiques de l'imaginaire occidental et du pays de Minas Gerais où se place Juiz de Fora : l'avenue offre un apprentissage dialogique péripatéticien gréco-ancien, tandis que les rues invitent à une flânerie et au footing d'une modernité européenne, au même temps que la rivière déborde une sexualité esclavagiste et coloniale brésilienne.
\end{abstract}

Mots-clés : paysage littéraire. A idade do serrote. Juiz de Fora (MG).

\section{INTRODUÇÃO}

A paisagem, em virtude de sua polissemia, tem sido objeto de estudo para inúmeras áreas do conhecimento. Concernente à ciência geográfica, a paisagem participou de seu período de institucionalização no século XIX, e como categoria analítica presenciou períodos de afirmação, estagnação e recuo de centralidade ao longo do desenvolvimento das correntes do pensamento geográfico (GONÇALVES, 2017). No campo da Geografia, a paisagem se estabelece como um de seus conceitos-chaves e uma categoria de análise das relações que se efetivam entre os processos naturais (bioquímicos e físicos) e sociais no espaço geográfico. Além disso, enquanto porção visível do espaço, constitui um dos mais importantes elementos da atratividade dos lugares.

Apesar das inúmeras conceituações acerca do termo 'paisagem', sua noção como herança traz importante contribuição à pesquisa ao compreendê-la como um documento histórico a ser interpretado. Autores como Ab'Sáber (2003, p.9) entendem-na "sempre como uma herança; como herança de processos fisiográficos e biológicos, é patrimônio coletivo dos povos que historicamente as herdaram como território de atuação de suas comunidades”. Na mesma lógica, Santos (2014, p.73) incrementa a sua historicidade como resultado acumulativo de 
tempo, indicando que "uma paisagem é uma escrita sobre a outra, é um conjunto de objetos que têm idades diferentes, é uma herança de muitos diferentes momentos."

A relação entre as áreas da Geografia e da Literatura não é recente, e segundo Collot (2012) há um importante número de trabalhos que tem sido consagrado ao estudo da inscrição da literatura no espaço e/ou à representação dos lugares nos textos literários. Ao utilizar a obra literária como um recurso ilustrativo complementar, assim como os mapas, as fotografias etc., a Geografia amplia seu instrumental na compreensão das intrincadas relações espaciais (LIMA, 2000). O fortalecimento de uma geografia literária é coerente com o desenvolvimento das ciências humanas e sociais, as quais se mostram há cerca de cinquenta anos cada vez mais atentas à inscrição dos fatos que tocam ao homem e à sociedade no espaço (COLLOT, 2012). Constata-se assim, segundo Collot (2012, p.19), uma significativa convergência entre as duas disciplinas: "os geógrafos encontram na literatura a melhor expressão da relação concreta, afetiva e simbólica a unir o homem aos lugares, e os escritores se mostram, do seu lado, cada vez mais atentos ao espaço em que se desenvolve a escrita". A respeito dos textos literários que envolvem representações espaciais, Marandola Jr. (2009) esclarece que toda esta linguagem literária engloba a linguagem geográfica.

Nesse sentido, torna-se fundamental, a partir do olhar de Collot (2012) que argumenta a favor de uma "Geografia Literária", compreender a evolução de práticas e formas de escrita que advogam a favor de uma melhor integração da dimensão espacial nos estudos literários, em três diferentes níveis complementares, a saber: geografia da literatura, geocrítica e geopoética. A geografia da literatura tem como objeto de estudo o contexto espacial onde as obras são produzidas, bem como o plano geográfico, histórico e sociocultural onde se situa, ou seja, tem preferência por refletir a respeito das enunciações nos textos. A geocrítica, perspectiva mais alinhada ao escopo deste trabalho, conforme será argumentado posteriormente, estuda as representações do espaço na própria constituição do texto e se vincularia, sobretudo, ao plano da história e do enunciado, isto é, do imaginário e da narrativa. Por fim, a geopoética busca discutir as relações das formas enunciativas dos espaços com os diversos gêneros literários.

Pensando na relação entre o estudo da paisagem e o da literatura, a análise oferecida pela perspectiva geocrítica, como defendida por Collot (2012, p.23), revela-se como aquela que pretende "estudar menos os referentes ou as referências de que o texto se nutre e mais as imagens e significações que ele produz, não uma geografia real mas sim uma geografia mais 
ou menos imaginária”. Nesse contexto, Gracq (1985 apud COLLOT, 2012) salienta que não existe nenhuma coincidência entre a planta de uma cidade que consultamos num folheto e a imagem mental que nos surge, na menção de seu nome, no sedimento deixado na memória por nossas caminhadas cotidianas.

Todavia, se formos em direção à uma crítica literária, este comentário deve ser lido com certa cautela, pois uma referencialidade é sempre necessária à produção discursiva de uma paisagem - é Umberto Eco (1994) quem levanta tal problemática, quando se indaga das possibilidades de se descrever uma árvore ou um rio sem nos servirmos de recursos do mundo concreto onde habitamos. Uma vez que não podemos escapar da linguagem, qualquer paisagem construída e descrita no plano do enunciado estará repleta de referências a um mundo possível (talvez o do próprio leitor), sendo a obra incapaz de trabalhar a descrição sem se servir de literalidade ou das figuras de linguagem (metáfora, analogias, metonímias...). Enquanto signo, a linguagem literária não pode estar totalmente autônoma ao mundo que a produz, e por isso a paisagem em um romance pode ser inventada, imaginada, idealizada, sonhada etc., mas ela sempre trará rastros e lastros que a remetem a algum tipo de comparação e sobreposição com o mundo concreto. Mas tal fato não inibe o ato criativo: se o significante é a parte do signo que permite o vínculo e trânsito paisagístico entre mundo concreto e diegético, o significado pode ser alterado e complementado da forma que atenda às demandas deste mundo possível que constitui a experiência literária.

Em outros termos: se a palavra "árvore" constitui vínculos entre leitor e narrativa, este significante pode estar atrelado à múltiplas tonalidades, outras formas de se fazer fotossíntese e de se posicionar em relação ao plano terrestre, trazendo um significado próprio e expressivo, uma vez que o referente deste signo não é o nosso mundo das leis terrestre, mas o da subjetividade e possível para o qual a obra aponta. A paisagem narrativa e imaginada está em algum lugar entre um referente que aponta para um mundo possível (nosso ou outros) e a subjetividade do narrador que a descreve e a insere em seu discurso, o que leva Souza (2013) a mencionar que "a componente visual não deve esgotar a dimensão conceitual da paisagem". De forma ainda mais clara, é necessário compreender que a contemplação romântica/ativa não se limita a uma simples apreensão visual da paisagem (COLLOT, 2014). Assim, a paisagem no enunciado foi interpretada em seu conteúdo e forma pelo narrador e, também, assim será interpretada pelos leitores. Xavier (2007) esclarece que interpretar a paisagem significa agregar valores ao que é percebido. 
Tendo em vista o contexto teórico mencionado, o artigo tem como objetivo possibilitar a identificação dos lugares ${ }^{1}$, atualmente dotados de valores comunitários, e que compõem a paisagem literária de Juiz de Fora (MG), consoante com o olhar do poeta Murilo Mendes e expresso em sua obra A Idade do Serrote.

Murilo Mendes (1901-1975) nasceu no dia 13 de maio, em Juiz de Fora, Minas Gerais, filho do funcionário Público Onofre Mendes e de Elisa Valentina Monteiro de Barros. Iniciou seus estudos em Juiz de Fora, e entre os anos de 1912 e 1915 tomou aulas de poesia e literatura com Belmiro Braga. Em 1917, mudou-se para Niterói e ingressou no Colégio Interno Santa Rosa. Em 1920, mudou-se para o Rio de Janeiro. Trabalhou como Arquivista no Ministério da Fazenda e foi funcionário do Banco Mercantil. No Rio começou sua carreira literária publicando alguns de seus poemas em revistas que estavam vinculadas ao movimento modernista: Verde e Revista de Antropofagia. Em 1930, Murilo publicou seu primeiro livro de poesias intitulado Poemas. Recebeu o Prêmio Graça Aranha com seu primeiro livro. Participou do Movimento Antropofágico, que buscava uma vinculação com as origens do Brasil.

A obra analisada - a Idade do Serrote, publicada em 1968 - destaca-se por apresentar trechos que descrevem paisagens e lugares da cidade de Juiz de Fora, por meio da perspectiva vivencial, memórias e olhares do autor que marcaram sua infância e juventude nas primeiras décadas do século XX. Através de seu "olhar precoce", da sua enorme vontade de conhecer e de seu exercício de voyeur e visionário, na visão do próprio poeta transformado em narrador de si, são descritas e encadeadas lembranças e percepções que "iluminam pessoas, situações, bichos e coisas, transpondo o vivido para figuras de sonho" (CARDOSO, 2003, p.7).

A paisagem provinciana relatada na obra, e que corresponde a Juiz de Fora do início do século XX, é repleta de informações culturais, que segundo Cardoso (2003, p.7),

se desprendem de suas referências histórico-geográficas, para compor o cotidiano
daquele 'menino experimental', que colava pedaços da Europa e da Ásia em grandes
cadernos, enquanto tentava 'pegar o som' da flauta de Isidoro e seguir o ritmo marcado
do 'Quindum sererê'.

Uma Juiz de Fora que dialogava a cultura europeia replicada dentro dos casarios dos bairros nobres com as ruas populares repletas de uma brasilidade cotidiana. Uma Juiz de Fora situada na encruzilhada entre mundos, como veremos nas análises que nos propomos.

\footnotetext{
${ }^{1}$ A utilização do termo lugar, nesta pesquisa, refere-se a sua compreensão como uma ideia mais ampla e que não deve ser entendida como "qualquer lugar" ou sinônimo abstrato de localidade. Compreende-se o "lugar", em concordância com Souza (2013), como um espaço dotado de significado e carga simbólica, ao qual se associam imagens, muitas vezes conflitantes entre si (boa fama x má fama; hospitaleiro x perigoso; etc.).
}

Malta; Fois-Braga, $2021 \quad$ ISSN 0104-5490 
A pesquisa foi elaborada tendo como início a construção do corpus teórico. Na sequência, realizou-se a leitura sistemática e o estudo do livro A Idade do Serrote, no intuito de identificar e pré-selecionar capítulos e/ou trechos e relatos que contemplassem as paisagens e lugares de Juiz de Fora, priorizando espaços públicos (ruas, avenidas, rios, etc.) em detrimento dos privados (casas; escolas; etc.). Buscava-se assim, identificar e mapear lugares por onde o autor transitava no início do século XX e que ainda persistem em sua importância simbólica no imaginário coletivo juiz-forano do século XXI (e.g. trechos do calçadão da Rua Halfeld; bairro Alto dos Passos, rio Paraibuna, Avenida Rio Branco etc.). Para além da simples citação a lugares e características fisiográficas da cidade, priorizou-se prosas e/ou trechos no qual o poeta emprega ampla descrição e exposição de memórias e impressões relacionadas a tais paisagens que recuperavam sua infância, mas que ainda reverberam como lugares afetivos da contemporaneidade. Na análise literária de cada uma destas categorias paisagísticas juiz-forana, buscou-se a elaboração de mapas mentais que propiciassem a leitura da conexão entre o relato das memórias do poeta acerca dos lugares selecionados e dos elementos da paisagem (material e simbólico-afetiva) associada.

\section{SOBRE CONCEITOS DE PAISAGEM LITERÁRIA:}

Inicialmente é de fundamental importância conceituar a concepção de espaço geográfico, que consiste em um "conjunto indissociável, solidário e também contraditório, de sistemas de objetos e sistemas de ações, não considerados isoladamente, mas como o quadro único no qual a história se dá" (SANTOS, 2002, p.63). A definição de Santos (2002) esclarece previamente que o espaço qualificado como geográfico, vai além da simples compreensão que o reduz apenas como a superfície terrestre. O espaço geográfico é visualizado como o resultado do desempenho do homem sobre a natureza, configurado como um sistema de ações, criando objetos técnicos que alteram a própria natureza e a sociedade humana (ROCHA, 2008).

$\mathrm{Na}$ escrita literária, o espaço é uma das categorias narrativas, chegando a constituir o que Bakhtin $(2011,2014)$ nomeia como cronotopos. A relação dos personagens com o tempo-espaço por onde transitam é primordial para a construção e desenvolvimento de suas ações, bem como para a sua transformação psicossocial. Visto como expressão de valores e de significações de um imaginário, portador de um potencial considerável de invenção linguística e formal, o espaço literário enquanto palco de representações e percepções pode, de acordo com Piatti et al. (2009), ser 
classificado em cinco categorias principais: i. o cenário que é o espaço onde as ações se realizam; ii. a zona de ação que é a combinação de todos os cenários (uma cidade inteira, uma região etc.); iii. o espaço projetado que existe em forma de lembranças, sonhos ou desejos dos personagens que não estão fisicamente presentes nesses cenários; iv. o marcador que é um lugar que não pertence às categorias anteriores, mas que indica a abrangência e o horizonte de um espaço de ficção; v. a rota pela qual os personagens se locomovem em modos distintos: a pé, no trem, no carro, no lombo de um cavalo etc.

A partir deste alicerce metodológico, é possível reconhecer e reconfigurar as demais categorias geográficas (território, paisagem, região e lugar) sem desconsiderar, no entanto, a existência de diversas correntes de pensamento geográfico (humanística, dialética marxista; geografia cultural). Nesta pesquisa serão detalhadas e abordadas, sobretudo, as categorias "lugar" e "paisagem".

Apesar do conceito de lugar possuir inúmeras interpretações ao longo do tempo e em distintos campos do conhecimento, a definição adotada para este estudo parte do pressuposto assinalado por Fremont (1980) que se refere à noção de "espaço vivido" e Tuan (1983, p.83) que complementa ao pontuar que "quando o espaço nos é inteiramente familiar, torna-se lugar". Lugar representa, portanto, o sentido de pertencimento, a identidade biográfica do homem com os elementos do seu espaço vivido.

\begin{abstract}
No lugar, cada objeto ou coisa tem uma história que se confunde com a história de seus habitantes, assim compreendidos justamente por não terem com a ambiência uma relação de estrangeiro. E reversivamente, cada momento da história de vida do homem está contada e datada na trajetória ocorrida de cada coisa e objeto, homens e objetos se identificando reciprocamente (MOREIRA, 1997, p.164).
\end{abstract}

Entretanto, a imagem de lugar e mesmo a ideia de lugar em si, apoia-se sobre um espaço material, porém, não se confunde inteiramente com ele (SOUZA, 2013). Ao rememorar os lugares de sua infância em Juiz de Fora, o poeta Murilo Mendes adota em sua obra uma compreensão de lugar que supera o sentido geográfico restrito de localização. Segundo Relph (1979), esta abordagem de lugar "não se refere a objetos e atributos das localizações, mas à tipos de experiências e envolvimento com o mundo, a necessidade de raízes, de segurança" (RELPH, 1979 apud LEITE, 1998, p.10).

\footnotetext{
${ }^{2}$ Para Fremont (1980, p. 17) o espaço vivido, em toda sua espessura e complexidade é capaz de revelar diversas camadas das realidades regionais: componentes administrativos, históricos, ecológicos, econômicos, mas também, e mais profundamente psicológicos.
} 
A paisagem, entendida inicialmente como expressão dos eventos nos lugares, deixa claro seu escopo, primordialmente, ligado às formas que a visão de um observador abarca e, portanto, traz um sentido fortemente visual (COSGROVE, 1998; SOUZA, 2003; ROCHA, 2008). Contudo, é fundamental observar, em concordância com Souza (2013), que a componente visual não deve esgotar a dimensão conceitual da paisagem. Neste sentido, é necessário e saudável "desconfiar" da paisagem, considerando, inicialmente, que ela representa uma forma captada pela visão. Seria conveniente e fundamental, conforme esclarece Souza (2013, p.48), "buscar interpretá-la ou decodificá-la à luz das relações entre forma e conteúdo, aparência e essência”. No entanto, a decodificação pressupõe a busca por meios para revelar algo já existente (GONÇALVES, 2017) e as representações literárias do espaço, bem como o exercício de mapear narrativas e as suas estruturas espaciais complexas representam tais instrumentos (PIATTI et al., 2009, p.177).

É notório mencionar que a paisagem representa um conceito-chave de expressiva centralidade para a ciência geográfica e possibilita a compreensão da relação sociedadenatureza em suas diferentes dimensões e alcance. No entanto, há que se perceber, que existem diferentes pontos de vistas e discursos acerca da paisagem, que complementam a concepção advinda da Geografia. Em um esforço de classificação e organização, autores como Besse (2014) admite a existência de 5 "portas da paisagem" que consistem em possíveis entradas ou problemáticas paisagísticas, sendo elas: i. a paisagem é uma representação cultural; ii. a paisagem é um território fabricado e habitado; iii. a paisagem é meio ambiente material e vivo das sociedades humanas; iv. a paisagem é experiência fenomenológica; v. a paisagem como projeto.

O autor busca ampliar a abordagem consensual que associa a percepção da paisagem, sobretudo, ao primado da visão e indica outras possibilidades de compreensão a partir da existência de paisagens sonoras, dos sabores e táteis. Apesar da coexistência de diferentes racionalidades paisagísticas, bem como de suas possibilidades analíticas, Besse (2014) reconhece a justaposição e a superposição desordenada desses diferentes discursos e pontos de vista sobre a paisagem.

Em um esforço semelhante ao realizado por Besse (2014), Gonçalves (2017) elenca quatro dimensões representacionais da paisagem: i. paisagem-forma; ii. paisagem-mosaico; iii. paisagem-herança; iv. paisagem-representação. Para tal, o pesquisador toma como ponto de partida a afirmação de Berque (1998) de que: "as paisagens enquanto representações de nossas $\begin{array}{lll}\text { Malta; Fois-Braga, } 2021 & 312\end{array}$ 
vidas cotidianas são pulsantes e cheias de significado". Reforça-se, portanto, que o discurso ou narrativa espacial demanda um "componente organizador", já que a paisagem por se tratar de uma abstração e valorização estabelecida por um processo de seleção e sintetização está sujeito a modificação ao longo do tempo (SANSOLO, 2007; GONÇALVES, 2017).

É necessário perceber, também, que a paisagem é reveladora, apesar de sempre "encobrir" determinados aspectos ao traduzir-se na representação seletiva ou "retocada" de si mesma ou por meio de intervenções no próprio substrato espacial material - ou seja, uma reformatação da paisagem na própria realidade (SOUZA, 2013, p.52). A afirmação é pertinente no âmbito desta pesquisa, pois ressalta a necessidade da investigação sobre as ausências intencionalmente presentes nas representações da paisagem, assim como se encontra retratada no texto literário de Murilo Mendes (GONÇALVES, 2017).

Visto algumas das entradas de compreensão das problemáticas que convivem na cultura paisagística contemporânea, será discutida a relação entre paisagem e lugar. A esse respeito Puntel (2007) esclarece que é a partir do estudo da paisagem que se torna possível começar uma reflexão sobre as variáveis que determinam cada lugar. O lugar mostra, então, por meio da "paisagem a história da população que ali vive, os recursos naturais de que dispõe e a forma como se utiliza tais recursos" (CALLAI, 2000, p.97). Dessa forma, compreende-se que a paisagem constitui conceitualmente um instrumento que auxilia a compreender o lugar vivido e que se encontra em constante mutação. Em complemento, é fundamental refletir que a paisagem contém os atributos do mundo vivido e de acordo com o axioma de Relph (1979, p.16 apud MARANDOLA JR., 2009): "Lugares têm paisagens, paisagens e espaços têm lugares". Nesse sentido, pensando na perspectiva da experiência e na relação com a arte literária, é chamada a atenção para a capacidade da literatura "chamar atenção para as áreas de experiência que de outro modo passaria despercebidos [...] uma função da arte literária é dar visibilidade a experiências íntimas, inclusive às de lugar" (TUAN, 1983, p. 180).

Já a respeito das relações entre Geografia e Literatura, concordamos com Marandola Jr. (2009), quando o pesquisador afirma que os elos entre ambas as áreas não se constituem apenas pela aproximação de dois campos do conhecimento, uma vez que ambos possuem suas especificidades, virtudes e limitações. Portanto, "ler literariamente a Geografia ou ler cientificamente a Literatura, numa transposição de discursos, produziria deformações e reduções, diminuindo assim a riqueza da interação e a sua permeabilidade" (MARANDOLA JR., 2009, p.488). Para Ferre (1946, p.10) citado por Collot (2012, p.21-22), a geografia literária Malta; Fois-Braga, $2021 \quad$ ISSN 0104-5490 313 
se baseia no postulado de que o contexto da produção literária influencia as próprias obras e, portanto, “[...] existem necessariamente relações entre toda obra humana e o meio terrestre em que se localiza, e que mesmo em seus aspectos os mais espirituais e os mais inauditos, a atividade dos homens não pode deixar de exprimir relações dessa natureza". Uma geografia verdadeiramente literária, desse modo, deveria integrar a dimensão subjetiva e imaginária, de acordo com Collot (2012) e que por conta dessas características se mostra difícil de cartografar, a menos que se apoie em um mapa mental. No mesmo sentido exposto por Marandola Jr. (2009) compreende-se que a literatura atua como complemento ou como fonte de informações (descrições e representações) do espaço.

Ao refletir sobre o conceito de paisagem no âmbito literário, a concepção de paisagem literária para Collot (2012, p.25), que toma por base a obra de Jean-Pierre Richard (1984), assume a seguinte expressão:

[...] não designa evidentemente o ou os lugares onde um escritor viveu ou conheceu em viagem e que pôde descrever em sua obra, mas uma certa imagem de mundo, intimamente ligada a seu estilo e à sua sensibilidade: não tal ou tal referente, mas um conjunto de significados e uma construção literária.

A composição da paisagem que neste contexto assume um caráter imaginário é, portanto, inseparável do texto. O leitor é convidado a ler na paisagem literária não apenas uma imagem de lugares ou um imaginário de espaço, mas uma configuração recíproca do mundo e da obra (COLLOT, 2012). A escrita é "uma forma de espacialização do sujeito, que tem a necessidade de se exprimir, de se projetar no espaço: o da página e o da paisagem" (COLLOT, 2012, p.28).

É necessário compreender como se dá a construção da paisagem literária de Juiz de Fora pelo poeta Murilo Mendes em sua obra. Para tanto, considera-se em conformidade com Bastos (1998, p.63) que a representação do espaço "não deve estar condenada a um processo exclusivo de descrição da paisagem, considerada como o aspecto mais visível do espaço. É possível e necessário apreender e revelar aspectos e traços humanos essenciais".

Questiona-se, portanto, se a paisagem de Juiz de Fora se encontra reduzida aos traços materiais marcantes da cidade ou, por outro lado, trata-se de uma imagem mais complexa e matizada, que toma emprestado algumas peculiaridades a certos lugares que Murilo Mendes pôde frequentar durante sua infância, nos livros e experiências vivenciadas, ainda que reelaboradas pelo seu imaginário de escritor (COLLOT, 2012). 


\section{A IDADE DO SERROTE COMO MEMÓRIA JUIZ-FORANA DO POETA:}

Na sua escrita memorialista, o poeta Murilo Mendes define-se como o menino de "olho precoce" (CARDOSO, 2003), o que já nos traz um vínculo com o ideário da paisagem captada pelas retinas, da observação atenta do mundo que o circunda e o constitui enquanto juiz-forano do início do século XX. A publicação da obra A Idade do Serrote, enquanto texto autobiográfico, logo, também autoficcional em certo nível, aproxima a trajetória literária de Murilo Mendes da dos principais integrantes do movimento modernista brasileiro. A Idade do Serrote, segundo Cardoso (2003, p.17), deve ser compreendida "menos como testemunho de uma circunstância histórica e mais como exposição de um processo de conhecimento, que, contrapondo-se aos padrões educacionais estabelecidos, vai construindo uma identidade poética”. Apesar de ser apresentada em prosa, é um texto poético, marcado pela sensibilidade que o autor sempre teve ao escrever seus poemas (DA SILVEIRA, 2014). Ainda que narrativo, não deixa de apresentar um narrador que se assemelha ao eu-lírico da poesia.

Outro aspecto que merece ser destacado na obra refere-se a descoberta do sexo como um elemento importante para a maturação do indivíduo. Em $A$ idade do serrote, segundo Teixeira (2005, p.84), "a recorrência das cenas que dão conta desse tema, deixa transparecer o quanto essa questão sexual é especialmente importante para a formação de Murilo Mendes”. Ressaltase, ainda, que a expressão idade do serrote tem uma conotação sexual e é usada para designar a adolescência como fase da vida em que os jovens se masturbam (TEIXEIRA, 2005).

$\mathrm{Na}$ obra, é perceptível a trama entre o encadeamento de suas lembranças e a intensidade “de percepções esparsas, que iluminam pessoas, situação, bichos, e coisas, transpondo o vivido para figuras de sonho" (CARDOSO, 2003, p.7). O cenário provinciano da infância relatado pelo poeta, conecta-se com:

\footnotetext{
[...] um mundo de informações culturais, que se desprendem de suas referências histórico-geográficas, para compor o cotidiano daquele 'menino experimental', que 'colava pedaços da Europa e da Ásia em grandes cadernos, enquanto tentava pegar o som da flauta de Isidoro e seguir o ritmo marcado do 'Quindum sererê'..' (CARDOSO, 2003, p.7).
}

Estas iluminações de momentos, pessoas, lugares fica expresso também na forma como a obra se anuncia: são blocos textuais que constituem um significado próprio, não dependentes do que vem antes ou depois dele. Ainda que a sequência dos blocos siga um fluxo inexorável das fases da vida, eles são semanticamente individualizados. São sequências e sobreposições 
que constituem o próprio ato de se lembrar, quase sempre em flashes. São camadas sobrepostas de lembranças, formatando uma Juiz de Fora palimpséstica: as linhas vazias e em branco entre as sentenças memorialísticas trazem o sentido estético destas multiplicidades de acontecimentos que ocorrem simultaneamente nos atos da vida do personagem em sua juventude e nas memórias do narrador, agora já adulto e distante da sua cidade natal.

$\mathrm{Na}$ obra fica claro o papel do poeta, adulto, artista reconhecido, que nos meados dos anos 1960 busca fixar seu retrato de criança (CARDOSO, 2003). É notório seu papel de voyer visionário que estende seu exercício de observar nos mais diversos lugares de seu cotidiano: o quintal da casa paterna, a escola, a missa de domingo ou a calçada da rua Halfeld.

Ao realizar a análise da obra por meio do recurso do rizoma ${ }^{3}$ textual, Antunes e Fiorese (2011) esclarecem que a escrita da memória se caracteriza pelos vínculos e enlaces que realizam o trânsito entre espaços, tempos e personas virtuais. Dentre os seis princípios ou características aproximativas apontadas pelos autores, menciona-se, para o presente estudo, o princípio da cartografia, uma vez que o "rizoma se assemelha antes a um mapa por possuir várias entradas e levar a múltiplos caminhos, construídos de acordo com a necessidade e o desejo" (ANTUNES e FIORESE, 2011, p.94). Para exemplificar o princípio de funcionamento do rizoma - a cartografia - os autores recorrem às diversas descrições da cidade de Juiz de Fora feitas pelo poeta.

Cita-se, desde referências acerca do modo de viver - "Juiz de Fora naquele tempo era um trecho de terra cercado de pianos por todos os lados" (MENDES, 2003, p. 61) - até às caracterizações históricas da "Manchester Mineira" das primeiras décadas do século XX (ANTUNES e FIORESE, 2011). É ressaltado que o rizoma textual de Murilo Mendes possibilita acessar a cidade e, consequentemente, suas memórias por diferentes entradas (ANTUNES e FIORESE, 2011, p.98), ou camadas, o que resgata esta paisagem palimpséstica.

Estas camadas devem ser escavadas, para assim darmos conta de melhor verificar as estruturas das paisagens juiz-foranas que constituem o imaginário de Murilo Mendes e que, de certa forma, ainda reverberam no cotidiano do século XXI. Neste processo de uma arqueologia da poética, ou de uma fenomenologia da imaginação poética, para mencionarmos Bachelard (1988), trechos representativos destas imagens da cidade encontram-se com maior intensidade nas seguintes camadas urbano-narrativas, ou seja, nos seguintes blocos semânticos da obra:

\footnotetext{
${ }^{3}$ Modelo descritivo ou epistemológico na teoria filosófica de Gilles Deleuze e Félix Guattari. 
Origem, memória, contato, iniciação; A Rainha do Sabão; Teresa - estas três prosas resgatam lugares de convívio e experiência da infância e adolescência do poeta em Juiz de Fora. Já os capítulos-paisagens nomeados como Primo Nélson e A rua Halfeld enunciam e constroem memorialisticamente a principal avenida (a Barão do Rio Branco) e a rua mais icônica do município.

Em a Origem, memória, contato, iniciação, o poeta apresenta sua origem e o universo simbólico que lhe constituiu. Como sintetiza Sacramento (1999, p. 83), “[...] o material sumariado [...] aflui ao texto, nos demais, através de uma espécie de memória involuntária desencadeada por nomes e cantigas que povoaram infância e adolescência de Murilo”. Já na prosa $A$ rainha do sabão, o poeta, assim como em outros momentos da obra, faz referência à imagem feminina e ao erotismo que ela enseja, situações recorrentemente vivenciadas ao longo de sua infância e adolescência. Assim, é destacado o erotismo representado pela exposição de "partes esotéricas" do corpo das lavadeiras e de suas amigas às margens do rio Paraibuna. Neste sentido, no capítulo Teresa o poeta realiza uma aproximação sintomática com o principal rio da cidade, o Paraibuna, quando relato o fim trágico de Teresa (figura a quem na adolescência o poeta sentia forte inclinação erótica), atirando-se de noite nos braços do então caudaloso rio.

Vemos que estes 03 capítulos esboçam uma sequência psicanalítico-narrativa. O sexo é a origem de tudo: da vida e dos desejos que a acompanham. Após vir ao mundo e nascer para o desejo, o poeta vive o corpo-cidade como local de um erotismo explosivo e disperso, até que posteriormente fixa o seu erotismo sexual em um único corpo (o de Teresa) e em um ponto específico da cidade (o Rio Paraibuna). Nestes capítulos temos, então, uma sequência de adequação e concentração do erotismo, pois a cidade é vivida pelo narrador-poeta enquanto etapas de um desejo que busca se vincular a um órgão, ou melhor, a um canto urbano. Como nos diz Kahn (2015, p. 53 e 54),

Freud utilizou o termo perverso polimorfo para descrever os primeiros prazeres das
crianças, obtidos por meio de outros órgãos que não os genitais. Ele queria dizer com
isso que todos os prazeres físicos que mais tarde se tornarão a primeira opção dos
adultos chamados de pervertidos estão incluídos no repertório infantil.

Assim, os desejos são experimentados na epiderme de um corpo urbano do poeta, que a vive sensorialmente em cada rua, canto e lugares, em um alter e autoerotismo disperso em diferentes partes de seu corpo diluído na e em fusão com a cidade. Posteriormente, este erotismo disperso se concentra em um local específico: o Rio Paraibuna, cujas águas escuras e então 
caudalosas caracterizam o início e o fim da vida. O rio com suas lavadeiras se torna o epicentro do seu erotismo urbano, o local do fluxo por onde o desejo sexual trafega com as tragédias de afogamento, onde as pulsões de vida e de morte vibram em conjunto.

Já o capítulo Primo Nélson nos apresenta um dos parentes que contribui à formação intelectual de Murilo Mendes, destacando-se mais uma vez a relação que o poeta mantém com o espaço e que varia conforme sua idade (TEIXEIRA, 2005). Nessa prosa, em específico, é ressaltada a Avenida Rio Branco, como cenário importante em onde se deram diversas conversas entre o poeta e seu primo, considerado uma das bases da sua formação intelectual e espiritual (TEIXEIRA, 2005). Ainda que com menor intensidade, a rua Direita (atual Avenida Rio Branco), também é mencionada em trechos da prosa $D u d u$, e por isso mesmo também recorreremos a ele.

No capítulo sobre A rua Halfeld, o poeta leva para o título o nome da principal via da cidade, baseando suas descrições em percepções sensoriais e deixando evidente sua importância simbólica: "Escrevo sobre a rua Halfeld sem situá-la no espaço, ocupando-me somente com as pessoas que a percorrem" (MENDES, 2003, p. 144). Por meio de um caminhar narrativo por tal rua, o poeta busca destacá-la, sobretudo, como local de encontro. Em sua prosa, ela é caracterizada como "um espaço capaz de representar a diversidade da cidade, sem sobrepô-la à descrição de personagens rememorados que circulam pela obra" (OLIVEIRA, 2006, p.50).

\section{PAISAGENS LITERÁRIAS DE JUIZ DE FORA EM A IDADE DO SERROTE}

Tendo em vista os objetivos estipulados, a crítica lítero-geográfica se pautará em analisar o sentido dos "lugares" supracitadas (o rio, a rua e a avenida), aqueles que compõem com maior intensidade a paisagem literária da Juiz de Fora de Murilo Mendes. Compreendemos que tais lugares representam a conformação entre os aspectos simbólico-afetivos e os de natureza concreta e material, apoiando-se em dois tempos narrativos: o do enunciado da vivência e o de sua enunciação. Assume-se como pressuposto, conforme a concepção humanista da geografia, que todo ambiente circundante ao homem, "seja físico, social ou imaginário, influencia sua conduta" (MELO, 2001, p.33), logo, a construção discursiva do poeta é influenciada tanto pelo ambiente narrado quanto pelo de onde ele narra. 
Dessa perspectiva, será analisada a relação estabelecida entre os elementos do espaço geográfico e as memórias (carregadas de simbolismo e significado) relatadas pelo poeta. $\mathrm{O}$ quadro 1 , sintetiza os elementos a serem trabalhados, bem como, principais aspectos da percepção da paisagem identificados.

\begin{tabular}{|c|c|c|}
\hline & Prosa & Porconcõo da naicaoem fícica / simbólica \\
\hline \multirow{3}{*}{$\begin{array}{c}\text { Rio } \\
\text { Paraibuna }\end{array}$} & $\begin{array}{l}\text { Origem, memória, } \\
\text { contato, iniciação }\end{array}$ & $\begin{array}{l}\text { a) Rio-afluente de águas pardas } \\
\text { b) Esforço/luta para desaguar-se no Rio Paraíba do Sul. } \\
\text { c) Sensação de pena do rio }\end{array}$ \\
\hline & A Rainha do Sabão & $\begin{array}{l}\text { a) Uso da margem direita do rio pelas lavadeiras } \\
\text { b) "Paraibunda": observação de certas partes esotéricas do corpo das } \\
\text { lavadeiras. } \\
\text { c) Erotismo como complemento da paisagem do rio. }\end{array}$ \\
\hline & Teresa & $\begin{array}{l}\text { a) Águas melancólicas } \\
\text { b) O episódio do suicídio de Teresa no rio faz com que o poeta sinta } \\
\text { ciúmes do Paraibuna. } \\
\text { c) Antropomorfização do rio que se igualara a um ser mitológico } \\
\text { capaz de respirar e possuir a jovem que se atirara em seus braços. }\end{array}$ \\
\hline $\begin{array}{c}\text { Avenida Rio } \\
\text { Branco }\end{array}$ & $\begin{array}{c}\text { Primo Nélson / } \\
\text { Dudu }\end{array}$ & $\begin{array}{l}\text { a) Avenida longuíssima de seis quilômetros de comprimento. } \\
\text { b) Referência espacial como local de passagem e pano de fundo dos } \\
\text { diálogos travados com o primo e passeios com o pai. } \\
\text { c) Sensação de familiaridade e segurança com o local que o } \\
\text { circundava. }\end{array}$ \\
\hline Rua Halfeld & A rua Halfeld & $\begin{array}{l}\text { a) Espaço de caminhada e de grande familiaridade desde a infância - } \\
\text { reta muito comprida. } \\
\text { b) Marcado pela imensidão de gente e de coisas. } \\
\text { c) Aspectos da industrialização precoce da cidade. } \\
\text { d) Múltiplas nuances da paisagem: sons, imagens, cheiros e } \\
\text { memórias. }\end{array}$ \\
\hline
\end{tabular}

Fonte: Resultados da pesquisa.

\section{O Rio Paraibuna}

A compreensão do significado do rio Paraibuna requer, inicialmente, o entendimento que os vocábulos água e rio possuem nos trechos analisados, considerando que o uso dessas expressões desempenha funções bastante simbólicas. De acordo com Chevalier e Gheerbrant (2019, p.15), “as significações simbólicas da água podem reduzir-se a três temas dominantes: fonte de vida, meio de purificação, centro de regenerescência". Nas diferentes prosas em que se identifica a menção ao Rio, é possível atribuir uma diferente dimensão simbólica associada à água. 
Na prosa Origem, memória, contato, iniciação, Mendes (2003, p.26) apresenta o rio como traço importante de sua identidade, ao relatar:

Nasci às margens de um rio afluente de águas pardas, o Paraibuna, que fazia muita força para atingir os pés do rio Paraíba. Dediquei-lhe na adolescência um minúsculo epigrama. Eu tenho uma pena do rio Paraibuna.

No primeiro fragmento, a água pode ser interpretada em coerência com o simbolismo das tradições judaica e cristã, ou seja, como origem da criação. Nesse sentido, a "água se torna o símbolo da vida espiritual e do Espírito, oferecidos por Deus e muitas vezes recusados pelos homens" (CHEVALIER e GHEERBRANT, 2019, p.17). O significado assumido pelo vocábulo "rio", ao mencionar sua relação com a bacia do rio Paraíba do Sul, reforça sua significância de que:

Seja a descer as montanhas ou a percorrer sinuosas trajetórias através dos vales, escoando-se nos lagos ou nos mares, o rio simboliza sempre a existência humana e o curso da vida, com a sucessão dos desejos, sentimentos e intenções, e a variedade de seus desvios (CHEVALIER e GHEERBRANT, 2019, p.781).

Ao constatar que sentia "pena" do rio, o poeta acrescenta à sua paisagem física relações afetivas pelas águas pardas e pelo trajeto persistente em meio à cidade até seu destino (bacia do rio Paraíba do Sul), uma afetividade topofílica de desgosto, tristeza e melancolia em relação a sua existência na cidade. O Rio tem personalidade e enquanto corpo sensível gera a compaixão do poeta.

Na prosa a Rainha do Sabão, o rio Paraibuna é mencionado novamente como palco das memórias do poeta, adquirindo agora novo significado simbólico e acrescentando outras características à paisagem.

[...] o tempo longínquo em que depois do período de concubina do mascate Salomão dominava barras de sabão lavando roupa com outras lavadeiras na margem direita do Paraibuna ou também Paraibunda pois ali se avistavam às vezes certas partes esotéricas do corpo das lavadeiras e suas amigas; [...] (MENDES, 2003, p.31).

No trecho, é destacado o uso da margem direita do rio pelas lavadeiras, costume comum à época e que o tornava um lugar de peregrinação e encontro, cuja lembrança do poeta revela

um comportamento comum aos meninos, cuja curiosidade fazia com que espreitassem com malícia as mulheres à beira do rio, na tentativa de, furtivamente, ver suas partes íntimas, possivelmente à mostra em função do trabalho e local em que estavam (TEIXEIRA, 2005, p.84). 
O significado simbólico associado à água neste trecho remete a valorização feminina, sensual e maternal e, sobretudo, da "[...] água como fonte de fecundação da alma: a ribeira, o rio, o mar representam o curso da existência humana e as flutuações dos desejos e dos sentimentos" (CHEVALIER e GHEERBRANT, 2019, p.21). Portanto, para além da materialidade da paisagem circundante composta pelo rio, as nuvens, a vegetação de sua encosta (mata ciliar) e a fauna, o poeta a descreve como profundamente simbólica, associada às suas memórias e no qual a água surge como "o símbolo das energias inconscientes, das virtudes informes da alma, das motivações secretas e desconhecidas" (CHEVALIER e GHEERBRANT, 2019, p.21). A imagem leva ao leitor à sensualidade das roupas molhadas que insinuam o corpo proibido e em trabalho, mas também causa em um plano mais profundo um certo estranhamento e inquietação: o rio de águas barrentas serve para lavar as roupas. A tensão dos binômios encontra-se para um duelo nas margens do rio.

Na última prosa selecionada, a passagem trágica que tem no rio o palco de sua realização, permite a interpretação simbólica da água em "dois planos rigorosamente opostos, embora de nenhum modo irredutíveis, e essa ambivalência se situa em todos os níveis. A água é fonte de vida e fonte de morte, criadora e destruidora" (CHEVALIER e GHEERBRANT, 2019, p.16).

\footnotetext{
Anos depois, sendo eu já morador no Rio, comendo e bebendo maus pensamentos soube que Teresa perturbada pela ruptura do noivado com um operário da Cervejaria Americana, atirara-se de noite nos braços do Paraibuna.

Tive ciúmes imediatos do Paraibuna que respirara e possuíra aquela dália morena, incorporando-a com avidez às suas águas melancólicas. Que não pudesse eu, já agora um ser mitológico, transformar-me em rio! (MENDES, 2003, p.155).
}

Há neste trecho clara alusão ao caráter purificador e regenerador da água por ela representar, ao mesmo tempo, morte e vida. O binômio que estava nas beiradas agora se apresenta dentro: nas margens do rio a água barrenta limpa as roupas ao longo dos dias, enquanto no seu leito, esta mesma água caudalosa recebe os corpos dos suicidas à noite. $\mathrm{O}$ poeta confere ao rio características antropomórficas e ao igualá-lo a sua condição, sente ciúme por ele ter se apoderado do seu objeto de desejo. A melancolia atribuída às suas águas remete novamente ao sentimento de pena que o poeta sente em relação ao rio e reforça o caráter dual e simbólico dos rios, apontado por Chevalier e Gheerbrant (2019, p.19), que "podem ser correntes benéficas ou dar abrigo a monstros". Considerando as principais características 
simbólicas da paisagem associadas ao rio Paraibuna, elaborou-se um mapa mental síntese disposto na figura 01 .

Figura 01 - Elementos da paisagem simbólica do Rio Paraibuna

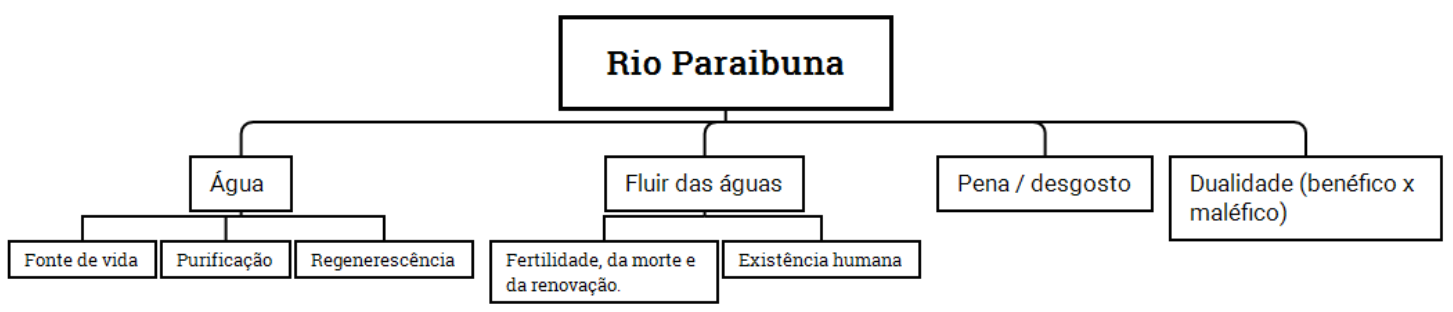

Fonte: Resultados da pesquisa.

\section{Avenida Barão do Rio Branco}

Na prosa sobre o primo Nélson, figura que exercia a função de mestre para o poeta e cuja amizade iniciada na infância perduraria na adolescência, a Avenida Rio Branco se apresenta como espaço narrativo para as conversas e ensinamentos. A mesma referência espacial surge em outros capítulos da obra, porém, com a sua antiga denominação de Rua Direita em decorrência das diferentes temporalidades assumida pela narrativa.

Primo Nélson nos anos sucessivos pegou o hábito de passear comigo depois do jantar, mormente na longuíssima avenida Rio Branco, de seis quilômetros de comprimento.

Primo Nélson, que cedo me transmitiu o vírus da literatura, dissera-me uma vez que "o universo cortado em fatias está a nossa disposição". Fatias: a arte, a ciência, a religião, a filosofia. Ele intuíra a unidade do conhecimento, percebera algo da visão universal das coisas; explicara-me essa doutrina, adaptando-a às minhas possibilidades da época. Não compreendi tudo direito, mas a semente ficou; e nossas conversas ao longo da avenida Rio Branco acham-se na base da minha formação espiritual. Que voltas me davam à cabeça! (MENDES, 2003, p.89).

O sentido da rua, sobretudo enquanto um espaço urbano apropriado pelo movimento, só é apreendido a partir de sua tensão com um outro que abriga o imaginário da imobilidade segura: a casa (DAMATTA, 1997, p.43). No pós-jantar, no início da noite, as caminhadas pela Avenida Rio Branco promovem um outro tipo de digestão: os das ideias filosóficas. $\mathrm{O}$ alimento para o 
corpo, sentado em casa na mesa de jantar, se complementa com aquele para o espírito: refeição em pé, andando pelas ruas.

Na prosa, fica explícito o vínculo que Murilo Mendes tinha pela via no início do século $\mathrm{XX}$, indicando uma cidade ainda provinciana e com laços de vizinhança bem estabelecidos entre a população residente.

Passeávamos em diálogo, topando feias, peixões, colegas, operários, meninas de laçarotes tangendo o arco, vendedores ambulantes com seus pregões. Todos se conheciam, Juiz de Fora parecia constituir uma única família (MENDES, 2003, p.86).

A avenida, então, se torna uma extensão da própria casa: o diálogo com o primo é o que define o seu caminhar, mas este é interrompido, sobreposto, retrocedido pelos encontros que marcavam pausas nestas instruções. E a paisagem que o autor relata indica um lugar de familiaridade e de uso cotidiano em virtude das funções estabelecidas pela rua (comércio e serviços), constituindo um espaço de encontro, convivência e de passagem de parte significativa dos moradores da época: "Saio a passeio com meu pai ao longo da conversadora rua Direita que me serve de salão, colégio e porto. Encontramos tanta gente" (MENDES, 2003, p.86).

A Avenida Rio Branco é um microcosmo, torna-se a própria cidade (casa, sala, colégio) e vai mais além (um porto, que situa a cidade mineira de Juiz de Fora em um imaginário litorâneo de chegadas e partidas). É, acima de tudo, um local de trocas pelas passagens, de convivência por encontros furtivos.

Figura 2 - Elementos da paisagem simbólica da Av. Rio Branco

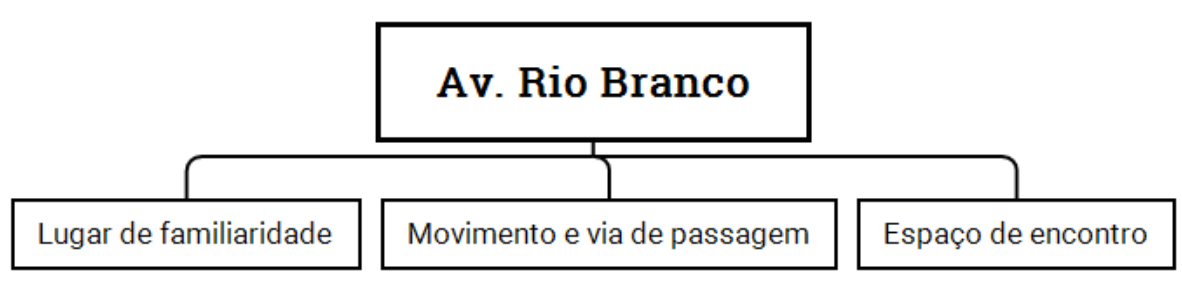

Fonte: Resultados da pesquisa.

\section{A Rua Halfeld}

Juntamente com a Avenida Rio Branco e o Rio Paraibuna, a Rua Halfeld constitui a terceira via na qual o poeta passa e se ancora - e não somente ele, haja vista que estes três topônimos constituem o próprio imaginário da cidade de Juiz de Fora. 
De acordo com Cosgrove (1998), as ruas representam uma criação racionalmente ordenada, designada e harmoniosa, cuja estrutura e cujo mecanismo são acessíveis a mente humana, assim como aos olhos. É nesta perspectiva do olhar e do se envolver sensitivamente com tais traçados que Murilo Mendes resgata das suas memórias de infância as ruas que percorria.

Se no Rio Paraibuna ele via as bundas (como ele nomeava: Paraibunda) das lavadeiras, e se na Avenida Rio Branco ele se instruía com o primo, por sua vez, na Rua Halfeld ele buscava construir uma apreensão da diversidade de rostos, trejeitos e profissões das pessoas que compunham esta grande família juiz-forana. Sobre tal rua Halfeld, ele comenta: "Faço o footing na rua Halfeld na minha infância e adolescência, os fundadores da cidade são alemães [...]" (MENDES, 2003, p.145). Apesar de delimitar a rua com indicadores geográficos e oferecendo uma origem germânica à Juiz de Fora, o poeta deixa claro qual o seu verdadeiro interesse com a descrição da paisagem rememorada:

Direi, entretanto, que a rua Halfeld é uma reta muito comprida, começando às margens do Paraibuna e terminando além da Academia de Comércio.

Escrevo sobre a rua Halfeld sem situá-la no espaço, ocupando-me somente com as pessoas que a percorrem (MENDES, 2003, p.152).

Há, também, trechos que remetem às caracterizações históricas da "Manchester Mineira" das primeiras décadas do século $\mathrm{XX}$, ao descrever elementos que compõem tal paisagem industrial:

[...] ouço as sirenes das fábricas apitando para o almoço: Juiz de Fora, dizem, antecipou-se a São Paulo em certos pontos da industrialização, conta com uma usina hidroelétrica além de muitas fábricas de tecidos, de cerveja, de móveis etc. [...] (MENDES, 2003, p.146).

A rua é caracterizada como um espaço marcado pelos apitos que constituem um ritmo para as atividades urbanas, logo, para os momentos de encontro com as diversidades de pedestres, que trazem até à vista do poeta uma variedade de rostos, imagens e sons:

[...] há certas pessoas obtusas que, sem o saberem, devido a uma reação contrária, excitam-me a inteligência, despertam-me o desejo de acelerar as ideias [...].

[...] passa Dona Aurélia D., uma montanha de babados, cheira a biscoito azedo.

[...] lá vem Justino, o vendedor de algodão, doce de nuvem, com a sua carrocinha, sempre embezerrado.

[...] a costureira Ricardina, feia, feiona, feíssima com uma cabeleira negra, negrona, negríssima de entontecer, até hoje não posso escrever sem um frisson a palavra cabeleira.

[...] Ricardo, o amolador de facas e canivetes, vai girando sua roda de pedra, aquele grito estrídulo, música atual, golpeia o ar. (MENDES, 2003, p.147-148). 
O significado simbólico do rosto, elemento que Murilo Mendes (2003) traduz ao caminhar na sua juventude pela rua Halfeld e que resgata nas suas memórias de escritor já adulto, é compreendido como "um desvendamento, incompleto e passageiro, da pessoa[...]" (CHEVALIER e GHEERBRANT, 2019, p.790). Por ser o rosto, a parte mais viva e mais sensível, o eu íntimo parcialmente desnudado, para compreendê-lo é preciso vagar, com paciência, respeito e amor (CHEVALIER e GHEERBRANT, 2019). Nas observações registradas na prosa $A$ rua Halfeld, a paisagem descrita não consiste apenas em elementos materiais presentes naquele espaço, mas nas pessoas e em seus rostos, como símbolo do mistério e uma "porta para o invisível” (CHEVALIER e GHEERBRANT, 2019).

Mas, os rostos que passam são antigos conhecidos, possuem nomes e personalidades individualizantes. $\mathrm{O}$ poeta os reconhece, é um reencontro casual estabelecido não necessariamente pelo ato de parar para conversar, mas simplesmente de se olharem e se perceberem enquanto presenças nas passagens urbanas. E, junto com estes encontros inesperados, todo um universo afetivo é acionado na mente do narrador. Enfim, não são passantes perfeitamente desconhecimentos, mas conhecidos imperfeitamente.

Figura 3 - Elementos da paisagem simbólica da Rua Halfeld

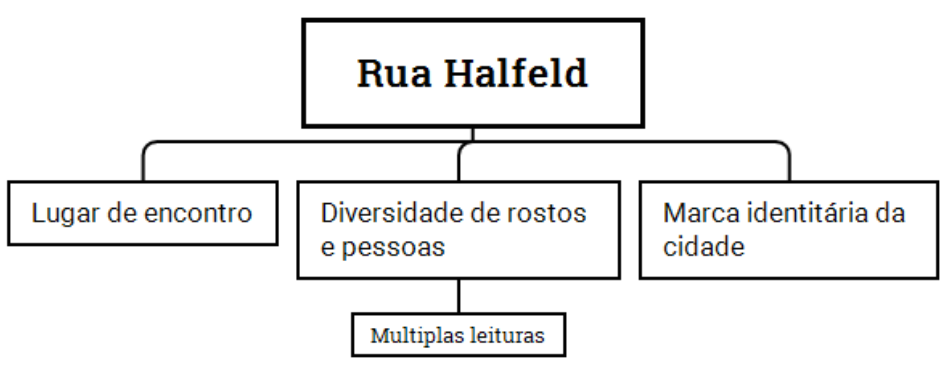

Fonte: Resultados da pesquisa.

\section{Considerações Finais}

A pesquisa apresentada buscou, a partir do estudo da paisagem descrita na obra de Murilo Mendes A idade do serrote, compreender aspectos materiais e afetivo-simbólicos relatados pelo poeta em suas memórias de infância e adolescência na cidade de Juiz de Fora do início do século XX. Para tanto, pautou-se no conceito de paisagem literária que percebe o leitor como um sujeito capaz de ler nesta paisagem, não somente uma imagem de lugares ou imaginário de espaço, mas um arranjo mútuo do mundo e da obra. Os lugares e paisagens juizforanas descritas 
e rememoradas por Murilo Mendes correspondem, portanto, a certa imagem daquela realidade, intimamente ligadas ao estilo e sensibilidade do poeta, correspondendo a um conjunto de significados e uma construção literária própria.

O poeta, na obra em estudo, buscou resgatar sua trajetória de vida e os ritos de passagem vivenciados pelo menino até alcançar a idade adulta, utilizando da escrita autobiográfica (talvez autoficcional) como uma forma de espacialização de suas memórias, expressando-se no espaço tanto da página quanto da paisagem. Entre os diversos lugares que foram tela para suas lembranças, selecionou-se o rio Paraibuna, a Avenida Rio Branco e Rua Halfeld como paisagens afetivo-simbólicas que representam a ligação do poeta com a sua terra-natal. Por meio destes lugares foram apontados elementos formadores da paisagem relatada pelo autor e a partir da elaboração de mapas mentais foram sistematizados os principais fundamentos do olhar do poeta e compõem tais paisagens literárias.

Percebemos que o poeta se comporta de maneira distinta em cada uma destas espacialidades, sendo seus vínculos desenvolvidos de maneira toponímica. No Rio Paraibuna, ele contempla a sexualidade mestiço-brasileira das lavadeiras paradas e debruçadas sobre as roupas que lavam, na Avenida Rio Branco, ele entra em diálogo com o primo que remete ao modelo da escola peripatética da antiga Grécia aristotélica, enquanto que na Rua Halfeld ele vive uma flânerie parisiense e um footing inglês entre os rostos dos passantes. Bundas, diálogos e footing-flâneur são termos que estabelecem um cronotopos (um tempo-espaço narrativo) na Juiz de Fora de Murilo Mendes que mescla nas paisagens da cidade do interior de Minas Gerais um corpo que se adapta aos modelos clássicos do aprendizado da Antiguidade com a Modernidade Europeia, parisiense e inglesa do século XIX, e com a sexualidade escravocrata e colonial do Brasil do início do século XX.

\section{REFERENCIAS}

AB'SÁBER, A. Os domínios de natureza no Brasil: potencialidades paisagísticas. São Paulo: Ateliê Editorial, 2003, p. 9-26.

ANTUNES, A. M.; FIORESE, F. A idade do serrote, de Murilo Mendes: a escrita da memória como rizoma textual. Revista Eletrônica Principia, 15, pp.93-98. 2011.

BACHELARD, G. A poética do espaço. São Paulo: Martins Fonte, 1988 [1957].

BAKHTIN, M. Estética da criação verbal. São Paulo: Ed. WMF Martins Fontes, 2011 [1979]. 
BAKHTIN, M. Questões de literatura e estética: a teoria do romance. São Paulo: Hucitec, 2014.

BERQUE, A. Paisagem-Marca, Paisagem-Matriz: elementos da problemática para uma geografia cultural. In: CORRÊA, R. L.; ROSENDAHL, Z. (orgs.). Paisagem, Tempo e Cultura. Rio de Janeiro: EDUERJ, 1998.

BESSE, J-M. O gosto do mundo: exercícios de paisagem. Rio de Janeiro: EdUERJ, 2014.

BESSE, J.-M. Entre a geografia e a ética: a paisagem e a questão do bem-estar. Trad. Eliane Kuvasney e Mônica Balestrin Nunes. GEOUSP - Espaço e Tempo. São Paulo, v.18 n.2 p.241$252,2014$.

CALLAI, H. C. Estudar o lugar para compreender o mundo. In: CASTROGIOVANNI, A. C. (Org.). Ensino de Geografia. Práticas e Textualizações no Cotidiano. Porto Alegre: Editora Mediação, 2000. p. 83- 131.

CARDOSO, M. R. Prefácio. In: MENDES, M. A idade do serrote. Rio de Janeiro: Record, 2003.

CHEVAlIER, J.; GHEERBRANT, A. Dicionário de Símbolos: (mitos, sonhos, costumes, gestos, formas, figuras, cores, números). Coordenação de Carlos Sussekind. Tradução de Vera da Costa e Silva, et al. - 32a . ed. - Rio de Janeiro: José Olímpio, 2019.

COLLOT, M. Rumo a uma geografia literária. Tradução de Ida Alves. Gragoatá Niterói, n. 33, p. 17-31, 2. sem. 2012.

COLLOT, M.., A. I., de M., M.J. and da SILVA, M.L.B., Poética e filosofia da paisagem. 2014

COSGROVE, D. A geografia está em toda parte: cultura e simbolismo nas paisagens humanas. In: ROSENDAHL, Z.; CORREA, R. L. (Org.). Paisagem, tempo e cultura. Rio de Janeiro: EDUERJ, 1998. p. 92-122.

DAMATTA, R. A casa e a rua. Rio de janeiro: Rocco. 1997.

DA SILVEIRA, L. R.; BATISTA, M. A Idade do Serrote, de Murilo Mendes, uma narrativa autobiográfica. Verbo de Minas, 15(26), pp.58-73.2014.

ECO, U. Seis passeios pelos bosques da ficção. Companhia das Letras, 1994.

FRÉMONT, A.; GONÇALVES, A.; MENDES, A. G. A região, espaço vivido. 1980.

GONÇALVES, E. S. Nuances e Dimensões da Paisagem na Produção do Conhecimento Geográfico. In: XVI Encuentro de Geógrafos de América Latina, 2017, La Paz. XVI Encuentro de Geógrafos de América Latina. La Paz: Instituto de Investigaciones Geográficas iigeo, 2017. v. 1. 
KAHN, M. Freud básico: pensamentos psicanalíticos para o século XXI. Rio de Janeiro: BestBolso, 2015.

LEITE, A. F. O Lugar: Duas Acepções Geográficas. Anuário do Instituto de Geociências UFRJ, 21, p. 9-20,1998.

LIMA, Solange Terezinha de. Geografia e Literatura: alguns pontos sobre a percepção da paisagem. Geosul, Florianópolis, v.15, n. 30, p. 7-33, jul/dez. 2000.

MARANDOLA JR, E.; GRATÃO, L. H. B. Geografia e Literatura: ensaios sobre geograficidade, poética e imaginação. Eduel. 2019

MARANDOLA JR, E. Geograficidade e espacialidade na literatura. Geografia, 34(3), pp.487508.2009.

MELO. V. M. Paisagem e simbolismo. In Paisagem, imaginário e espaço. Organizadores, Zeny Eosendahl, Roberto Lobato Corrêa. Rio de Janeiro: Ed. UERJ, 2001.

MENDES, M. A idade do serrote. Editora Companhia das Letras, 2018.

MOREIRA, R. Da Região à Rede e ao Lugar (A nova realidade e o novo olhar sobre o mundo). Revista Ciência Geográfica, AGB-Bauru/São Paulo, v. III, n.6, p. 01-11, 1997.

PIATTI, B.; BÄR, H. R..; REUSCHEL, A.-K.; HURNI, L.; CARTWRIGHT, W. Mapping literature: towards a geography of fiction. In: CARTWRIGHT, W.; GARTNER, G.; LEHN, A., orgs. Cartography and art. Berlin: Springer, 2009, p.177-192

OLIVEIRA, G. R. de. Memória e Identidade em a Idade do Serrote, de Murilo Mendes. Dissertação de Mestrado. Centro de Ensino Superior de Juiz de Fora. 2006.

PUNTEL, G. A. A paisagem no Ensino da Geografia. Ágora (UNISC. Online), v. 13, p. 283298, 2007.

RELPH, E. C. As bases fenomenológicas da Geografia. Geografia, 4(7), pp.1-25, 1979.

ROCHA, J. C. Diálogo entre as categorias da Geografia: espaço-território-paisagem. Caminhos de Geografia, v. 9, n. 27 set/2008 p. 128 - 142.

SACRAMENTO, O. A. do. A memória solidária: uma leitura da A idade do serrote de Murilo Mendes. Em Tese, Belo Horizonte, v. 4, p. 85-92, dez. 1999. Disponível em: Acesso em: 14 fev. 2011.

SANSOLO, D. G. Significados da paisagem como categoria de análise geográfica. Niterói: ANPEGE, s.n.t. 2007. 
SANTOS, M. A natureza do espaço: técnica e tempo, razão e emoção. São Paulo: Edusp. 2002 p. 384

SANTOS, M. Metamorfoses do Espaço Habitado: Fundamentos Teóricos e Metodológicos da Geografia. 6. ed. 2. Reimp. São Paulo: - Editora da Universidade de São Paulo, 2014 [1988].

SOUZA, M. L. de. Os conceitos fundamentais da pesquisa sócio-espacial. 2013.

TEIXEIRA, E. R. O poeta Murilo Mendes na revelação autobiográfica de a idade do serrote (Dissertação de Mestrado). 2005.

TUAN, Y-Fu. Espaço e lugar. São Paulo. Difel, 1983. 